\title{
The Importance of Recognising Depression in Adolescents Affected by Parental Illness
}

\author{
David Morley ${ }^{\#}$, Crispin Jenkinson \\ Department of Public Health, Old Road Campus, University of Oxford, Headington, UK \\ Email: "david.morley@dph.ox.ac.uk
}

Received July $17^{\text {th }}$, 2012; revised August $16^{\text {th }}$, 2012; accepted September $12^{\text {th }}, 2012$

\begin{abstract}
Research focusing on the impact of parental illness has increased rapidly in recent years, with studies on a range of both chronic and acute illnesses having now been reported. A key and consistent finding is the elevated risk of depression that young people face when adjusting to and living with a parent experiencing such a condition. Examples from the literature include studies focusing on parental multiple sclerosis, Parkinson's disease, stroke, cancer, affective disorder and traumatic brain injury. Such a body of literature emphasises the need to recognise and manage the increased risk of depression that young people face when confronted with such parental conditions and that a more family centred approach to parental illness is required. Additionally, it is important that the potential threat parental illness poses to young people's mental well-being is reflected in relevant clinical guidelines.
\end{abstract}

Keywords: Adolescent; Depression; Parental Illness

Depression in adolescence is largely characterised by features similar to those in adults. Low mood, lack of interest in activities, low self-esteem, inability to concentrate, suicidal thoughts, disturbed sleep, changes in appetite and feelings of guilt are just some such characteristics. In addition, adolescents can often appear agitated, may refuse to go to school and demonstrate behavioural problems (Thapar, Collishaw, Potter, \& Thapar, 2010).

Alongside early adulthood, adolescence is the most prevalent period for depression (Hammen, 1997). Importantly, unrecognised depression during this period of development can lead to poor educational attainment and psychosocial outcomes, as well as continued depressive disorder in adulthood (Birmaher, Ryan, Williamson, Brent, \& Kaufman, 1996). This highlights the need for its detection and treatment, and data indicates that at least $12 \%$ of adolescents report a minimum of low level depression (Sihvola et al., 2007). However, depression in childhood and adolescence frequently goes undiagnosed (Kramer \& Garralda, 2000), and this is compounded by the fact that adolescents are unlikely to consult general practitioners about mental health problems (Potts, Gillies \& Wood, 2001).

Research focusing on the impact of parental illness has increased rapidly in recent years. Data from a number of studies suggests young people experience a range of issues such as changing roles, heightened responsibility and reduced independence (Morley, Selai, Schrag, Jahanshahi, \& Thompson, 2011). However, a key and consistent finding is the elevated risk of depression that young people face when adjusting to and living with a parent experiencing serious illness. Studies across a range of parental conditions, both chronic and acute, appear to confirm this.

As a relatively well investigated parental condition, multiple sclerosis (MS) provides a sound example. Adolescent offspring

\footnotetext{
*Conflict of interests: None

${ }^{\#}$ Corresponding author.
}

of people with MS report significantly higher levels of depression than children of healthy parents (Yahav, Vosburgh, \& Miller, 2007). Other studies confirm these elevated levels through comparisons with the normal population (Morley et al., 2011). Evidence suggests that the risk of such mental health problems is, in part, associated with the mental health of both the affected and non-affected parent, and that where both parents report depressive symptoms the prevalence of internalising disorders in their offspring is two to three times higher than that found in the normal population (Steck et al., 2006).

MS is just one example of a parental condition that may have an effect on young people's mental well-being. Evidence from the literature suggests a wide range of conditions can have such an effect. For example, studies focusing on Parkinson's disease (Schrag, Morley, Quinn \& Jahanshahi, 2004; Morley et al., 2011), stroke (Visser-Meily et al., 2005a; Visser-Meily et al., 2005b), cancer (Visser et al., 2005), affective disorder (Beardslee Gladstone \& O’Connor, 2011) and traumatic brain injury (KiefferKristensen, Teasdale, \& Bilenberg, 2011) all report data where adolescent depression is a prominent feature. Such findings have important implications. The key to the effective management of depression in young people is its recognition and treatment (Rowe, Tonge, \& Melvin, 2004). In the United Kingdom, National Institute for Health \& Clinical Excellence (NICE) guidelines reiterate this in recommending that "healthcare professionals in primary care, schools and other relevant community settings should be trained to detect symptoms of depression, and to assess children who may be at risk of depression" (NICE, 2005: p. 149). Given the findings from a number of studies, young people confronted with parental illness certainly appear at increased risk of mental health problems, and should be recognised as such. As a starting point, the treatment of a serious medical condition requires far greater emphasis on not just the ill parent but on the wider family unit. A family centred approach at diagnosis should lead to a family centred approach to care. It is a priority that the potential impact of parental illness 


\section{MORLEY, C. JENKINSON}

on young people's mental health is recognised in relevant clinical guidelines, something that is currently lacking in, for example, UK guidelines for Parkinson's and stroke.

Adolescence can be a particularly turbulent period of development for some without the presence of serious parental illness. This only reiterates the importance of ensuring that young people confronted with parental illness receive the support that many are likely to require.

\section{REFERENCES}

Beardslee, W. R., Gladstone, T. R., \& O’Connor, E. E. (2011). Transmission and prevention of mood disorders among children of affectively ill parents: A review. Journal of the American Academy of Child and Adolescent Psychiatry, 50, 1098-1109.

doi:10.1016/j.jaac.2011.07.020

Birmaher, B., Ryan, N., Williamson, D., Brent, D. \& Kaufman, J. (1996). Childhood and adolescent depression; a review of the past 10 years. Part II. Journal of the American Academy of Child and Adolescent Psychiatry, 35, 1575-1583. doi:10.1097/00004583-199612000-00008

Hammen, C. (1997). Children of depressed parents: The stress context. In S. Wolchik, \& I. Sandler (Eds.) Handbook of children's coping (pp. 131-157). New York: Plenum Press.

Kieffer-Kristensen, R., Teasdale, T. W., \& Bilenberg, N. (2011). Posttraumatic stress symptoms and psychological functioning in children of parents with acquired brain injury. Brain Injury, 25, 752-760. doi:10.3109/02699052.2011.579933

Kramer, T., \& Garralda, M. (2000). Child and adolescent mental health problems in primary care. Advances in Psychiatric Treatment, 6, 287294. doi:10.1192/apt.6.4.287

Morley, D., Selai, C., Schrag, A., Jahanshahi, M., \& Thompson, A. (2011). Adolescent and adult children of parents with Parkinson's disease: Incorporating their needs in clinical guidelines. Parkinson's Disease, 2011, 951874. doi:10.4061/2011/951874

National Institute for Health \& Clinical Excellence (2005). Depression in children and young people: Identification in primary, community and secondary care. London: HMSO.

Potts, Y. Gillies, M., \& Wood, S. (2001). Lack of mental well-being in 15-year-olds: An undisclosed iceberg? Family Practice, 18, 95-100. doi:10.1093/fampra/18.1.95

Rowe, L., Tonge, B., \& Melvin, G. (2004). When should GPs prescribe SSRIs for adolescent depression? Australian Family Physician, 33, 1005-1008.

Schrag, A., Morley, D., Quinn, N., \& Jahanshahi, M. (2004). Impact of Parkinson's disease on patients' adolescent and adult children. Parkinsonism \& Related Disorders, 10, 391-397. doi:10.1016/j.parkreldis.2004.03.011

Sihvola, E., Keski-Rahkonen, A., Dick, D., Pulkkinen, L., Rose, R., Marttunen, M., \& Kaprio, J. (2007). Minor depression in adolescence: Phenomenology and clinical correlates. Journal of Affective Disorders, 97, 211-218. doi:10.1016/j.jad.2006.06.019

Steck, B., Amsler, F., Grether, A., Dillier, A., Baldus, C., Haagen, M., Diareme, L., Tsiantis, J., Kappos, L., Burgin, D., \& Romer, G. (2006). Mental health problems in children of somatically ill parents, e.g. multiple sclerosis. European Child \& Adolescent Psychiatry, 16, 199207. doi:10.1007/s00787-006-0589-5

Thapar, A., Collishaw, S., Potter, R., \& Thapar, A. K. (2010). Mangaing and preventing depression in adolescents. British Medical Journal, 340, 254-258. doi:10.1136/bmj.c209

Visser, A., Huizinga, G. A., Hoekstra, H. J., van der Graaf, W. T., Klip, E. C., Pras, E., \& Hoekstra-Weebers, J. E. (2005). Emotional and behavioural functioning of children of a parent diagnosed with cancer: A cross-informant perspective. Psychooncology, 14, 746-758. doi:10.1002/pon.902

Visser-Meily, A., Post, M., Meijer, A., Maas, C., Ketelaar, M., \& Lindeman, E. (2005a). Children's adjustment to a parent's stroke: Determinants of health status and psychological problems, and the role of support from the rehabilitation team. Journal of Rehabilitation Medicine, 37, 236-241. doi:10.1080/16501970510025990

Visser-Meily, A., Post, M., Meijer, A., van de Port, I., Maas, C., \& Lindeman, E. (2005b). When a parent has a stroke: Clinical course and prediction of mood, behavior problems, and health status of their young children. Stroke, 36, 2436-2430. doi:10.1161/01.STR.0000185681.33790.0a

Yahav, R., Vosburgh, J., \& Miller, A. (2007). Separation-individuation processes of adolescent children of parents with multiple sclerosis. Multiple Sclerosis, 13, 87-94. doi:10.1177/1352458506071163 